\title{
TESIS DEL CRITÓN SOBRE EL DEBER DE OBEDIENCIA A LAS LEYES DEL ESTADO Y LAS SENTENCIAS DE SUS JUECES
}

\section{Lo más importante no es vivir, sino vivir bien}

Sócrates y Critón, ${ }^{1}$ íntimo suyo, conversan en la celda donde el primero espera el momento en que su sentencia de muerte ha de cumplirse. Acaba de romper el día. Cuando el segundo llega al calabozo, Sócrates duerme de modo apacible. Su amigo aguarda a que despierte. Al abrir aquél los ojos, se sorprende de que Critón esté a su lado. ¿Cómo es que el alcaide lo dejó entrar? Critón explica que tiene sobre el carcelero alguna influencia $y$, cuando el filósofo pregunta al visitante por qué no lo despertó de inmediato, éste le responde: -Yo, en tu lugar, temería ser despertado, porque salir de mi sueño sería volver al sentimiento de mi infortunio. —¿Por qué has venido tan temprano?, inquiere Sócrates. - Para traerte una terrible nueva, contesta Critón. - ¿Acaso ha llegado de Delos el buque cuyo retorno marcará el momento de mi muerte? ${ }^{2}$-No, responde Critón, pero, por lo que cuentan los que vienen de Sunion, la nove llegará hoy, así que mañana, Sócrates, tendrás que beber la cicuta. - No creo que la nave llegue hoy, contesta el prisionero; sé que llegará mañana, como lo colijo de un sueño que tuve durante la noche: una hermosa mujer, toda vestida de blanco, me llamaba para decirme: ¡Sócrates, dentro de tres días estarás en la fértil Ftíal ${ }^{3}$

Critón anuncia que el carcelero ha sido sobornado, y que es preciso abandonar la prisión esa misma noche. - Si te niegas a huir, es seguro que muchas gentes, que no nos conocen bien ni a ti ni a mí, pensarán que, pu-

1 “Critón era un hombre de posición y riqueza, devotamente ligado a Sócrates, y a quien mucho interesaban las cuestiones filosóficas. Diógenes Laercio (II, 121) da una lista de 17 diálogos sobre temas de filosofia atribuidos a aquél, pero Platón lo representa como persona de carácter afable y sentido común práctico, totalmente desprovista de originalidad y sin ningún talento para la investigación." Harold North Fowler, "Introduction to the Crito", en la traducción inglesa del Eutifrón, la Apologia, el Critón, el Fedón y el Fedro, Loeb Classical Library, Harvard University Press, MCMLXVI, p. 148.

2 Cada año, como una especie de procesión religiosa, era esta nave enviada a Delos, y durante el viaje de la misma ninguna ejecución por delitos contra el Estado podía realizarse.

3 Ftía, antigua ciudad de Tesalia, patria de Aquiles. Tal mención, dentro del sueño de Sócrates, debe interpretarse, según Hermann Gaus, como augurio de una vida mejor después de la muerte. Gaus, Philosophischer Handkommentar zu den Dialogen Platos (Comentario filosófico manual a los Diálogos de Platón), Erster Teil, Zweite Hälfte, Kapitel II, p. 73. Cfr. Homero, Iliada, IX, 363. 
diendo salvarte gracias a mis bienes de fortuna, me abstuve de hacerlo. $Y$ nada es más indigno que tener más amor al dinero que a los amigos. Además, el pueblo jamás podrá creer que fuiste tú el que no quiso salir de aquí cuando te rogué que lo hicieras.

- ¿Debemos tener tanto aprecio a la opinión del pueblo?, pregunta Sócrates. - No hay que despreciarla, arguye Critón, porque el pueblo es capaz de ocasionar los mayores males a quienes han caído en desgracia. - No los puede causar, replica Sócrates, porque de él no depende hacer a los hombres sabios o insensatos. 4

Critón trata de convencer al preso de que no debe temer que, por salvarlo, sus intimos corran algún riesgo, y añade que, si se niega a evadirse, no sólo será injusto consigo mismo y hará el juego a sus malquerientes, sino que cometerá una iniquidad con sus hijos, al convertirlos voluntariamente en huérfanos.

-Si concuerda con la justicia, Critón, contesta el filósofo, tu solicitud es laudable; pero, si se aleja de ella, sólo puede ser reprensible. Tendré, pues, que examinar si debemos hacer lo que pretendes, porque bien sabes que no es de ahora mi costumbre de ceder solamente ante razones que, seriamente analizadas, me parezcan correctas. ${ }^{5}$ ¿No hemos dicho mil veres nive no hay que estimar las opiniones de todos, sino sólo las de los sabios? ¿No son las de éstos más respetables que la del vulgo?... Y, de no atenernos a las primeras, ¿no arruinaremos lo que no vive ni adquiere nuevas fuerzas en nosotros sino por la justicia? ¿Vamos a creer que esta parte nuestra, cualquiera que ella sea, en que la justicia y la injusticia residen, es menos noble que el cuerpo?... No debemos, pues, curarnos de lo que el pueblo diga, sino únicamente de lo que pueda decir ese supremo juez que es la verdad. Se argüirá que el pueblo tiene el poder de hacernos morir. ${ }^{*}$ Pero, aunque así fuera, existe una máxima que jamás debe olvidarse: lo más importante para el hombre no es vivir, sino vivir bien. $Y$ vivir bien no es otra cosa que hacerlo noble y justamente. ${ }^{7}$

Examinemos esta primera parte de la argumentación socrática.

Sócrates recuerda, ante todo, que en vez de seguir las opiniones, que pueden ser verdaderas o falsas, se rige por principios cuya verdad ha establecido de antemano. Las creencias, propias o ajenas, no deben ser aceptadas sin crítica. Lo que vale no es la $\delta o ́ \xi \alpha$, aun cuando sea compartida por el

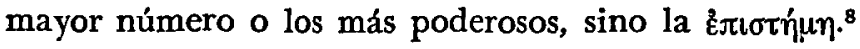

4 Cfr. Criton, $44 \mathrm{D}$.

5 Cfr. Criton, $46 \mathrm{~B}$.

6 Cfr. Critón, $48 \mathrm{~B}$.

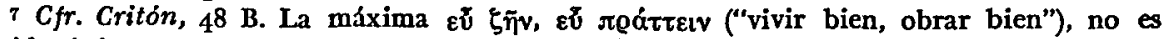
referida únicamente por Aristóteles al individuo, sino a la pólis. El fin de ésta -escribe"no es simplemente la vida, sino la vida valiosa", Politica, 1280 a 32.

8 El saber del filósofo -decia José Gaos jugando elegantemente con el sentido eti- 
Critón asegura que, de negarse a escapar, Sócrates sería injusto consigo mismo. Lo que aquél no comprende es que el filósofo sólo cometería una injusticia consigo mismo si faltase a sus convicciones. Tampoco comprende que, al morir en defensa de éstas, no será injusto con sus hijos. Del bienestar material y de la educación de los huérfanos cuidarán las amistades del prisionero. Él no tiene bienes de fortuna, pero dejará a sus vástagos una herencia mucho más valiosa: la ejemplaridad de su vida y de su muerte. ${ }^{9}$ No olvidemos las palabras que, al concluir su defensa, Sócrates dirigió a sus jueces: "Cuando mis hijos lleguen a la pubertad, castigadlos, señores, acosándolos con los mismos argumentos con que yo os he acosado a vosotros, si os pareciere que les preocupan las riquezas o cualquiera otra cosa más que la virtud; y si juzgan ser algo no siendo nada, reprochádles, como yo a vosotros, que no se preocupen de lo que deben y que piensan valer sin tener ningún mérito. Si hacéis estas cosas, tanto a mí como a mis hijos nos retribuiréis como es debido." 10

\section{El Estado es como un padre, a quien hay que venerar y obedecer}

Sócrates prosigue su argumentación con estas palabras: "¿Diremos que de ningún modo se debe cometer intencionalmente una injusticia, o que de una manera sí y de otra no? ¿O proceder de modo injusto no es nunca bueno ni honrado?" 11 Si esto fue antes muchas veces convenido por nosotros, ‘acaso pasamos por alto "que cuando creíamos discurrir seriamente como hombres maduros, en nada diferíamos de los niños?"

Critón se muestra de acuerdo, y Sócrates sienta el principio de que jamás se debe cometer una injusticia. ${ }^{12}$ Habrá, pues, que examinar si lo que Critón propone es justo o injusto y, en consonancia con tal principio, decidir si Sócrates debe o no huir de la cárcel.

Pero hay otro punto que exige esclarecimiento. El que es víctima de una injusticia, ¿debe responder con otra, como piensa el vulgo, o nunca se ha de proceder injustamente? Si es cierto que en todo caso se debe obrar bien, jamás será justo que el que padece un mal lo devuelva a quien lo causó, ya que "hacer mal a los hombres en nada difiere de ser injusto con

mológico de la palabra principios_- es un saber principal o principesco. Sobre la diferencia entre $\delta \delta \xi \alpha$ y $\varepsilon \dot{\tau} \tau l \sigma \tau \eta \dot{\eta} \eta$, cfr. I. M. Crombie, An Examination of Plato's Doctrines (Un examen de las doctrinas platónicas), Londres, Routledge \& Kegan Paul, 1969, I, p. 102.

9 "La muerte de Sócrates —escribe Mario Meunier- fue la última y la más elocuente de todas sus lecciones" (Meunier, La leyenda de Sócrates, Aguilar, Madrid, sin fecha, p. 156). 10 Apologia, $41 \mathrm{E}$.

11 Critón, 49 A. Todos los pasajes del Critón aqul citados fueron traducidos directamente del griego por el autor de este artículo.

12 Cfr. Critón, 49 B. 
ellos". ${ }^{13}$ Por tanto, ni se debe retribuir la injusticia con la injusticia ni hacer el mal a nadie, aunque por culpa ajena se sufra cualquier cosa. ${ }^{14}$

Una vez que Critón ha aceptado lo anterior, Sócrates pregunta:

Al salir nosotros de la cárcel, desobedeciendo a la pólis, “¿no procederemos mal con algunos, y precisamente con aquellos con quienes menos se debe?" 15

Como Critón declara no entender la pregunta, Sócrates la explica de este modo: "Si estando nosotros a punto de huir de aqui, o como se deba llamar esto, acercándose las leyes y el Estado entero, ${ }^{16}$ preguntarán: 'Díme, Sócrates, ¿qué tienes en mente hacer? ¿Acaso, por medio de esta acción que intentas, no planeas, en lo que de tu parte está, acabar con nosotras las leyes y con el Estado entero? ¿O te parece posible que subsista y no vaya a la ruina aquel Estado en que las sentencias dictadas nada valen, sino que pierden su eficacia por obra de los particulares?'." 17

Queda así circunscrito el problema central del coloquio: ¿es posible dejar al arbitrio de los particulares el cumplimiento o la violación de las leyes de la pólis y el respeto o el desacato a las sentencias de sus jueces? $O$, expresádo cn otro giro: ¿tienen aquéllos indefectiblemente el deber de someterse a lo que resuelvan el legislador y el magistrado? $\mathrm{Y}$, si tal obligación existe, ¿cómo puede fundamentarse?...

En rigor, más que de una, parece que aquí se trata de dos cuestiones:

$1^{\text {a }}$ Si los particulares deben siempre cumplir lo que los nómoi dispongan.

$2^{\mathrm{a}} \mathrm{Si}$ están en todo caso obligados a acatar las resoluciones de los jueces.

Aun cuando podría -o debería - argüirse que el segundo de tales deberes deriva, de modo mediato, de la ley, el problema realmente es uno, puesto que estriba en inquirir si el joגítns está siempre obligado a someterse al orden legal de la pólis. Las sentencias de los tribunales únicamente tienen fundamento cuando constituyen un acto de aplicación de los preceptos rectores del asunto que resuelven. Aquéllas son, como diríamos hoy, normas individualizadas o especiales; los nómoi, por el contrario, son preceptos generales y abstractos. ${ }^{18}$ Platón recuerda el vínculo entre las dos especies de

13 Idem.

14 Critón, 49 C.

15 Critón, $50 \mathrm{~A}$.

16 Esta personificación de las leyes y el Estado -afirma Taylor citando a Burnetes, en principio, un "mito" platónico. Artísticamente, el cuadro que Platón nos pinta tiene el propósito de provocar "una disposición de ánimo adecuada a la elevación de las exigencias éticas que el socratismo dirige a la conciencia". A. E. Taylor, Plato. The Man and his Work (Platón. El hombre y su obra), Methuen, Londres, 1960, p. 171.

17 Critón, 5o A-5o B.

18 El concepto de "ley especial o particular" se encuentra ya en Aristóteles. En su Retórica, 1376 b 7-9, escribe : "El contrato es una ley especial o particular, y no dan los contratos fuerza obligatoria a la ley, sino las leyes a los contratos que se ajustan a ella." 
normas, al mencionar "esa ley que ordena que las sentencias dictadas tengan eficacia". ${ }^{19}$

Mas, ¿qué puede decirse cuando el Estado es injusto y no emite correctamente su fallo? ¿Sostendremos que ello nos exime del deber de obediencia? ${ }^{20}$

Con la primera de estas preguntas, Sócrates vuelve, en realidad, a los dos puntos que anteriormente distinguimos, pues el Estado puede ser injusto o al expedir las normas que han de regir la conducta de los particulares, o cuando sus jueces hacen una aplicación defectuosa de las que regulan el caso de que conocen. Tanto en el Critón como en la Apología, es fácil percatarse de que el Filósofo de la Academia está convencido de la rectitud y santidad de las leyes, pues éstas, más que resultado de un acto legislativo en la acepción actual del término, son viejas formulaciones de lo que la inspiración religiosa y el sentido de justicia de hombres de otras épocas supo descubrir para regular en la mejor y más sabia de las formas la vida de los ciudadanos en el seno de la pólis. ${ }^{21}$ Es cierto que, precisamente en el Critón, ${ }^{22}$ el autor del diálogo admite que una ley puede ser injusta, en la medida, al menos, en que es obra humana y, por ende, perfectible. De aquí que hable

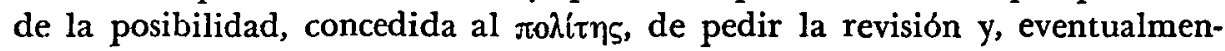
te, la reforma de los preceptos que los particulares consideren inconvenientes o inicuos. ${ }^{23}$ Pero tales deficiencias no deben atribuirse al espíritu ni, menos aún, a la esencia de la ley, sino a la falibilidad del hombre. Cosa parecida ocurre cuando los jueces, torciendo el sentido del nómos aplicable al hecho que deben juzgar, emiten una sentencia injusta. $Y$ es que, hablando con rigor,

19 Critón, $50 \mathrm{~B}$.

20 Cfr. Criton, 50 B-5o C.

21 Refiriéndose a los términos nómos y dike, Ernest Barker escribe: "Dikē muestra lo que es justo en casos reales o singulares; nómos es una formulación o asignación de posiciones. Dik $\vec{e}$ se mueve e inclina hacia el caso 'como la flexible regla de plomo que usaban los constructores lesbios'; nómos tiene, en cambio, la rigidez de una regla general. Dikē habla a través del dikasterion; nómos, a través de una antigua formulación escrita o de una vieja y no escrita regla consuetudinaria de igual validez y generalidad. Según veremos, nomos no significa legislación, en el sentido que damos hoy a esta palabra; y debe advertirse que una legislatura con sesiones constantes y regularmente encargada de hacer leyes, en modo alguno era una institución de la pólis griega. Más que un acto legislativo contemporáneo, nómos es una vieja formulación, y una formulación que rebasa el ámbito jurídico y puede penetrar en los dominios de la ética social. (Aristóteles puede, por ello, establecer vínculos entre la educación y el espíritu de las leyes, y decir que éstas 'tratan de formar ciudadanos buenos y justos'.) En cualquiera de estos dos aspectos; nómos difiere de lex, que significa promulgación o acto legislativo contemporáneos, especificamente juridicos en su sentido y en su alcance." The Politics of Aristotle. Translated with an Introduction, Notes and Appendixes by Sir Ernest Barker, Oxford, at the Clarendon Press, reprinted 1968, Introduction, IV, p. LXXI.

22 Cfr. Critón, 51 C.

23 En conexión con este punto, Erik Wolf dice: "En Atenas existía legalmente la posibilidad de reformar o de formular de nuevo cada af́o las leyes que eran consideradas como inconvenientes o no equitativas." Platón, "Frühdialoge und Politeia", en Griechisches Rechtsdenken (Pensamiento juridico griego), IV, I, p. 73, nota 8. 
la injusticia no es entonces imputable a la norma, sino a quienes, por torpeza, ignorancia o mala fe, no supieron entender ni respetar sus prescripciones.

Suponiendo que alegásemos que el Estado es injusto o que el juez no ha emitido correctamente su fallo, ¿qué contestaríamos si las leyes dijeran: "AAcaso esto había sido convenido por nosotras y por ti, o hay que atenerse a las sentencias que el Estado dicte?" ${ }^{24} \mathrm{Si}$ tal pregunta nos asombrara, probablemente aquéllas añadirían: "¿Censurando qué cosa a nosotras y al Estado pretendes arruinarnos? En primer lugar, ¿no fuimos quienes te hicimos nacer, y no fue por obra nuestra que tu padre tomó por esposa a tu madre y te procreó?..." 25

Si el hombre nace y crece bajo la protección de los nómoi; si son éstos los que regulan el matrimonio de los padres y lo concerniente a la crianza del hijo y a la educación, ¿no se sigue de todo ello que el ciudadano tiene el deber de someterse a lo que prescriban? Quien ha vivido al amparo de las leyes y con su obediencia demuestra que las considera irreprochables, ¿cómo podría alegar más tarde que no está obligado a cumplirlas? "¿Qué clase de sabio eres - preguntan a Sócrates_ que te ha permanecido oculto que la patria es más digna de honores y también más venerable y santa y tenida en mayor estima entre los dioses y los hombres inteligentes que la madre y el padre y todos los ancestros juntos?" 28 .

No debe olvidarse, como dice Sir Ernest Barker, que, para los griegos, la comunidad es "participación de una sustancia espiritual común que aquélla ha heredado y tiene la misión de trasmitir. Es una comunidad porque heredó esa sustancia; y porque tiene la misión de trasmitirla es, también, una estructura educativa". ${ }^{27}$ Pero la sustancia de que Barker habla no les parecía una simple "abstracción", sino "algo concreto que encarnaba en la ley", ya en la escrita, ya en la no escrita. El nómos "es la fuerza cohesiva del Estado"; por obra suya, la sociedad existe y se mantiene unida. ${ }^{28}$

A la patria "conviene reverenciarla, obedecerla y alabarla cuando se irrita, y ello en mayor grado que al padre; y o persuadirla o ejecutar lo que mandare; y padecer, guardando silencio, si ordena sufrir algo, ya sea ser golpeado o encadenado; y que si te condujere a la guerra para ser herido o muerto, así debe hacerse, y que esto es lo justo y no debe uno ceder ni abandonar su puesto, sino que, tanto en la guerra como en el tribunal o en cualquiera otro sitio, debe cumplirse lo que prescribieren el Estado y la

24 Critón, $50 \mathrm{C}$.

25 Critón, $50 \mathrm{D}$.

26 Critón, $5^{1}$ A- 51 D.

27 Barker, Greek Political Theory (Teoria politica griega), Methuen \& Co. Ltd., 1970, p. 42 .

28 Barker, obra citada en la nota anterior, p. 43 . 
patria, o persuadirla en cuanto existe algo que es justo por naturaleza; ${ }^{29}$ pero que es impío usar la fuerza contra la madre o contra el padre, y mucho más aún que contra éstos contra la patria". ${ }^{30}$

EI ciudadano es, pues, como un hijo de la pólis; existe por ella y para ella, y los incontables beneficios que de la misma recibe lo obligan a obedecer sus preceptos, igual en tiempos de paz que en épocas de beligerancia; a aceptar los castigos que le imponga si comete injusticias, y a no escatimar ningún sacrificio, incluso el de la vida, cuando la patria está en peligro.

La primera de las razones que aquí se aducen para justificar el deber de respeto a los nómoi es, como diríamos hoy, de orden moral. Ante la importancia de los beneficios recibidos, la gratitud nos obliga. Si, para gozar de tales dones, nos mostramos conformes con las leyes; si nada tenemos que censurarles ni nos dan motivo para persuadirlas a que nunca ordenen lo que se opone a la naturaleza, ¿con qué fundamento pretenderemos eludir sus mandatos?

En el pasaje à que se refiere esta glosa dibújase ya la idea de que al lado o por encima de lo justo legal existe lo justo por naturaleza; parece afirmarse, igualmente, la superioridad de esta última forma de justicia y, por tanto, proclamarse el principio de que, cuando el legislador se aparta de lo justo natural, pueden los particulares tratar de convencerlo de que se ha equivocado. ${ }^{31}$

En todo el diálogo, Platón habla, indistintamente, de los deberes del hombre frente al Estado y la patria, y emplea estos términos como intercambiables. Ello no es sino consecuencia de la tesis de que el Estado es como un padre, a quien hay que venerar y obedecer aún en mayor medida que a todos los ancestros juntos.

\section{Doctrina del pacto tácito}

El relato prosigue así: "Considera entonces, Sócrates, añadirían probablemente las leyes, si esto que decimos es cierto, que con lo que ahora traes entre manos no pretendes hacernos nada justo. Pues aunque te hicimos nacer, te criamos, te educamos y te hicimos participar de todo lo bueno para ti y para los demás ciudadanos, sin embargo, públicamente hemos declarado que si alguno de los atenienses, después de reflexionar bien y de haber considerado los asuntos del Estado y a nosotras las leyes, encuentra que no somos de su gusto, tiene la facultad de marcharse, tomando sus cosas, e ir a donde quisiere." 32

29 Estas palabras demuestran que, para Platón, lo justo legal puede, a veces, no coincidir con lo justo natural.

so Critón, 51 C.

31 Recuérdese lo dicho en la nota 23.

32 Critón, 5 I C-51 D. 
Aun cuando no se puede dejar al arbitrio de los particulares el acatamiento o el desacato a las leyes, éstas, las de Atenas, siempre han proclamado que el individuo a quien le desagraden los asuntos públicos o la legislación, es libre de emigrar o de irse a una colonia. El deber de respeto está, pues, condicionado por una especie de pacto tácito. ${ }^{33} \mathrm{Si}$ un ciudadano no hace uso de tal permiso, y viendo la forma en que los jueces emiten sus resoluciones y el legislador formula los nómoi, sigue viviendo en la pólis, con toda justicia se podrá decir que, de hecho, ha acordado que hará lo que se le ordene.

La obligación de obediencia a la pólis y a su sistema normativo tiene un triple fundamento: ${ }^{34}$ el que no la cumple es injusto, primero, porque olvida que el Estado es como su progenitor; segundo, porque no sólo nació bajo la protección de sus normas, sino que, de acuerdo con éstas, se le crió y educó, asegurando así su desarrollo intelectual y físico; y, tercero, porque habiendo convenido tácitamente en obedecer, ni cumple con las leyes ni las përsuade de que no han regulado bien los asuntos públicos. Además, pese a que le conceden la facultad de elegir entre obedecer o irse a otra parte, llevando consign sus pertenencias, no hace uso de esta opción.

El último de los tres fundamentos cobra especial fuerza en el caso de Sócrates, porque el filósofo, más que cualquiera otro de los atenienses, convino, no de palabra, sino con hechos, en respetar el compromiso de lealtad y obediencia que contrajo. La prueba es que permaneció siempre en su ciudad; jamás salió de sus límites, salvo para ir a la guerra. Nunca emprendió viajes, como todo el mundo, ni experimentó el deseo de conocer otro Estado, ya que Atenas y sus leyes le agradaban, por lo que, al amparo de éstas, procreó a sus hijos e hizo todo lo demás. ${ }^{35}$

No por medio de actos esporádicos, sino a través de setenta años de vida, durante los cuales le habría sido lícito alejarse, aceptó, tácitamente,

33 Sobre la doctrina platónica del pacto tácito: A. E. Taylor, Plato. The Man and his Work (Platón. El hombre y su obra), Methuen, Londres, 1926, reprinted 1960, pp. 171173; Alfred Verdross-Drossberg, Grundlinien der Antiken Rechts- und Staasphilosophie (Fundamentos de la antigua filosofia del derecho y del Estado), Springer Verlag, Viena, 1948, pp. 66-69; Adolf Menzel, Calicles. Contribución a la historia de la teoria del derecho del más fuerte, trad. Mario de la Cueva, Centro de Estudios Filosóficos de la Universidad Nacional Autónoma de México, 1964, pp. 88-92. (Fs interesante comprobar, en estas páginas, las semejanzas que Menzel encuentra entre la doctrina platónica del pacto tácito y las ideas de los sociólogos franceses Léon Bourgeois y Alfred Fouillée.) I. M. Crombie, $A n$ Examination of Plato's Doctrines (Examen de las doctrinas platónicas), Londres, Routledge \& Kegan Paul, 1962, reprinted 1969, I, pp. 181-182; Erik Wolf, Griechisches Rechtsdenken (Pensamiento juridico griego), Vittorio Klostermann, Frankfurt am Main, 1968, IV, I, pp. 70-72.

34 Cfr. Critón, 51 E-52 A.

35 Cfr. Critón, 52 C. "El que mostró, respecto de su patria, la obediencia de un niño, es Sócrates, el más libre de todos los mortales, que no obedecía sino a su razón." Wilamowitz Moellendorf, Staat und Gesellschaft der Griechen (Estado y sociedad de los griegos), p. 53, cita de Barker en la p. zo de la obra a que remite la nota 27 . 
someterse al orden legal de su ciudad y, por tanto, a las sentencias dictadas de acuerdo con éste. No prefirió ni a Lacedemonia ni a Creta, cuya "eunomía" alabó siempre, sino que se ausentó de Atenas "menos aún que los cojos, los ciegos y los demás lisiados". ${ }^{36}$

Después de recordar a Sócrates los beneficios recibidos y el testimonio de una conducta diuturna, las leyes le señalan qué consecuencias resultarian para él si accediese a huir de la cárcel sin el permiso de los atenienses. Ni se haría bueno a sí mismo ni beneficiaría a sus amigos, pues es indudable que correrían el peligro, ya de ser desterrados, ya de perder su fortuna. En caso de escapar a otra ciudad, a Tebas o a Megara, por ejemplo, todo el mundo miraría con recelo al recién llegado, considerándolo como un destructor del orden legal. Además, con su conducta, confirmaría la opinión que tuvieron sus jueces, al grado de que "les parecería haber emitido correctamente su veredicto". ${ }^{37}$ Por otra parte, no faltaría quien hiciese al fugitivo el siguiente reproche: ¿Cómo es posible que tú, un viejo al que queda tan poco tiempo de vida, te hayas atrevido a desear vivir más, "violando así las leyes de mayor rango"? 38

Si Sócrates arguyese que quiere salvarse en atención a sus hijos, para criarlos y educarlos, es seguro que las leyes le preguntarían: “¿Pues qué? ¿Acaso llevándolos a Tesalia los criarás y educarás, convirtiéndolos en extranjeros, a fin de que también gocen de ello? ¿Crees que, si son criados aquí, viviendo tú, serán mejor criados y educados, pese a no estar en tu compañía? Seguramente tus amigos los cuidarán. Pero, tes que sólo los cuidarán si partes hacia Tesalia y no si vas a la región de los muertos?" 39

Las leyes de Atenas concluyen su admonición con estas palabras:

"Persuadido por nosotras tus educadoras, Sócrates, no tengas en más a tus hijos ni el vivir, ni ninguna otra cosa frente a lo justo, a fin de que, yendo hacia el Hades, puedas alegar todas estas razones en tu defensa a los que allí gobiernan; pues haciendo esto aquí no parecerá mejor, más justo o más santo ni a ti ni a ningún otro de los tuyos, ni lo será tampoco cuando hayas llegado allá. Si partes ahora, te vas víctima de una injusticia, no de nosotras las leyes, sino de los hombres. Pero si te alejas tan vergonzosamente, devolviendo la injusticia y el mal sufridos, violando tus propios acuerdos y convenciones, que con nosotras celebraste, y causando mal a quien menos se debía, a ti mismo, a los amigos, a la patria y a nosotras, entonces, si vives, nos disgustaremos contigo, y allá, nuestras hermanas, las leyes del Hades, no te recibirán con benevolenecia, sabiendo que también trataste, en 
cuanto estuvo en tus manos, de destruirnos. Y que Critón no sea quien te persuada a hacer lo que dices, sino más bien nuestros argumentos." 10

4. El Critón y algunas teorias modernas sobre la seguridad jurídica y el reconocimiento de la obligatoriedad de las leyes por los particulares

Se ha discutido ${ }^{41}$ si, en el diálogo que estamos comentando, Platón esboza o no una tesis sobre ese valor que los autores modernos designan con el nombre de seguridad juridica. ${ }^{42}$ Aun cuando, como es obvio, el término no aparece en el coloquio platónico, sería incorrecto sostener que en tal opúsculo no se hacen consideraciones sobre los requisitos condicionantes de la seguridad y de la subsistencia misma del Estado. Corroboran este aserto tres pasajes del Critón:

1) "Dime, Sócrates, ¿qué tienes en mente hacer? ¿Acaso, por medio de esta acción que intentas, no planeas, en lo que de tu parte está, acabar con nosotras las leyes y con el Estado entero? ¿O te parece posible que subsista y no vaya a la ruina aquel Estado en que las sentencias dictadas nada valen, sino que pierden su eficacia por obra de lús pârticulares?..." 43

2) "¿Censurando qué cosa a nosotras y al Estado pretendes arruinarnos?..." 44

3) "En primer lugar, tú mismo, si te dirigieras a Tebas o a Megara - pues ambas tienen buenas leyes - llegarás, Sócrates, como enemigo de su régimen, y los que se preocupan de sus propios Estados te mirarán con recelo, considerándote destructor de las leyes, y confirmarás la opinión de tus jueces, al grado de que les parezca haber emitido correctamente su veredicto. Pues cualquiera que sea destructor nuestro, seguramente parecerfa también corruptor de los jóvenes y de los hombres de poco juicio." 45

No es posible expresar más diáfanamente la idea de que ningún Estado puede conservarse si los particulares desconocen la fuerza vinculante de sus leyes y se niegan a cumplir las sentencias que, de acuerdo con éstas, dicten los jueces. El desconocimiento del orden legal y el desacato a las resoluciones judiciales a la postre tienen como consecuencia la ruina de la pólis. Al culpable de aquel desconocimiento y de este desacato no sólo se le verá como un destructor de la legalidad, sino que con toda razón podrá motejársele de corruptor de la juventud. La seguridad y la existencia del Estado exigen, pues, que los particulares, en cumplimiento del pacto que con las

40 Critón, 54 B-54 D.

41 Cfr. E. Wolf, op. cit., IV, I, p. 65.

12 Cfr. Franz Scholz, Die Rechtssicherheit (La seguridad jurldica), Walter de Gruyter, Berlín, 1955; E. G. Máynez, Filosofía del derecho, Porrúa, 1974, cap. VII, 11, pp. 477-48.1.

43 Critón, $50 \mathrm{~A}$.

14 Critón, 5o C.

45 Critón, $53 \mathrm{~B}$. 
leyes tácitamente celebraron, ajusten su conducta a las prescripciones del legislador y a las sentencias de los jueces, incluso cuando los últimos, por ignorancia o mala fe, tuercen el sentido de tales prescripciones.

Entre la tesis platónica que acabamos de exponer y las doctrinas modernas sobre la seguridad jurídica existen, sin embargo, hondas diferencias. Muchas de las segundas tienen como base una concepción relativista de los valores que el derecho debe realizar $y$, de acuerdo con tal relativismo, sus partidarios afirman que las exigencias de la seguridad a menudo entran en pugna con las de la justicia, y deben prevalecer sobre las últimas. Si ni la ciencia ni la filosofía pueden enseñarnos qué es lo justo - dijo alguna vez Gustavo Radbruch - la voluntad y el poder son los llamados a decidir qué ha de valer como derecho. ${ }^{46}$ Platón, en cambio, está convencido de la rectitud y la santidad de los nómoi, y jamás duda de la objetividad de la justicia. Cierto es que admite, precisamente en el Critón, que una ley o una sentencia pueden ser injustas; pero, en su concepto, ello no debe atribuirse al espíritu ni, menos aún, a la esencia de las leyes, sino a falibilidad del

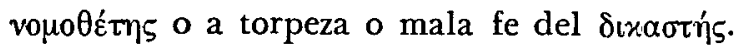

El sociólogo contemporáneo Teodoro Geiger habla de dos dimensiones dë la seguridad jurídica. A una le da el nombre de seguridad de orientación o certeza del orden; a la otra, el de seguridad de realización o confianza en el orden. ${ }^{47}$ Platón sólo alude a la segunda de tales dimensiones, puesto que hace depender la seguridad y subsistencia del Estado del fiel cumplimiento, por parte de los súbditos, de los preceptos del legislador y de las sentencias de los magistrados. El buen ciudadano contribuye con su comportamiento a la realización del orden normativo de la pólis, y confía en la bondad de las leyes como un hijo en la bondad de sus padres.

En el Critón no aparece, en modo alguno, la idea de un posible conflicto entre la seguridad y la justicia; es claro, en cambio, el pensamiento dë que la rectitud y santidad de los nómoi son la mejor garantía de que serán cumplidos.

Las palabras que -al personificarlas - el Filósofo de la Academia pone en labios de las leyes, no son las de un tirano, sino las de un educador. Las leyes de Atenas no pretenden un ciego acatamiento; tratan de persuadir y admiten la posibilidad de ser persuadidas. $Y$ si exigen tanto de los particulares, si se reservan la potestad de castigarlos cuando son injustos y esperan que en caso de guerra mueran en defensa de la patria, es porque les han dado cuanto necesitan para convertirse en hombres de bien y en buenos ciudadanos. Aquellas palabras las dice Sócrates, quien revela su convicción, al

46 Cfr. G. Radbruch, Rechtsphilosophie (Filosofia del derecho), K. F. Koehler Verlag, Stuttgart, 1956, I, 9, pp. 168 ss.

47 Th. Geiger, Vorstudien zu einer Soziologie des Rechts (Estudios preliminares para una sociologia del derecho), H. Luchterhand Verlag, Neuwied am Rhein und Berlín, 1964, p. 101 . 
pronunciarlas, de que las leyes de su ciudad no son válidas porque él las obedezca, sino que él las obedece porque son válidas.

Este resultado nos lleva, como de la mano, a una segunda cuestión: ¿hasta qué punto cabe afirmar que la tesis del pacto tácito coincide con las doctrinas modernas sobre el reconocimiento de la validez de las leyes?

Entre aquélla y éstas es notoria una diferencia. De acuerdo con la tesis platónica, el reconocimiento de la obligatoriedad de los nómoi por los sometidos a su imperio es un deber del súbdito, y tal deber deriva del pacto tácitamente celebrado por quienes pasan su vida en la pólis sin hacer uso de la absoluta libertad de migración que las leyes les conceden. Según las doctrinas modernas sobre el reconocimiento, en cambio, el orden legal no vale por sí mismo, sino sólo en la medida en que los particulares reconocen su fuerza vinculante. Dichas doctrinas parten, pues, del supuesto de que el legislador no puede obligar a quien no admita que sus mandatos son válidos. En el sentir de Platón, por el contrario, las leyes deben ser reconocidas no sólo porque los súbditos han convenido tácitamente en aceptarlas, sino además, y sobre todo, porque son intrínsecamente valiosas.

La idea de que los preceptos del derecho positivo no engendran, en cuanto tales, obligación ninguna, ha sido defendida con gran calor por quienes sostienen, como Rodolfo Laun, que sólo la voluntad de los destinatarios, en cada caso de aplicación, puede convertir el mandato heterónomo en ley autónoma. "Un imperativo, en sentido lingüístico - escribe Launes o heterónomo, en cuyo caso no puede implicar un deber, o implica un deber, pero entonces no puede ser heterónomo. Si tratamos de traducir este pensamiento de los filósofos al español, podemos decir lo que sigue: una frase que me ordena algo es o expresión de una voluntad ajena, en cuyo caso no me puede obligar, o me obliga, pero entonces no puede ser expresión de una voluntad extraña." ${ }^{48}$ Aun cuando la voluntad del legislador se manifieste gramaticalmente bajo la forma de imperativos hipotéticos, éstos no son en sí normas auténticas, porque lo que en realidad expresan es la voluntad de un sujeto que, no por el hecho de que puede constreñirme a la ejecución de lo que quiere, está en condiciones de obligarme en conciencia. Para que los mandatos legales puedan realmente ser obligatorios para mi, es, pues, necesario que yo, por un acto de autonomia, transforme el querer ajeno en querer propio o, en otras palabras, convierta en "autónoma" la exigencia "heterónoma".40

Sin duda podría decirse, volviendo al diálogo platónico, que la permanencia de un ciudadano en la pólis, el constante disfrute de los beneficios que ésta le brinda y la tácita renuncia a la facultad de migración, son mani-

48 R. Laun, Derecho y moral. Trad. J. J. Bremer, Centro de Estudios Filosóficos de la UNAM, México, 1959, p. 10.

19 R. Laun, op. cit., pp. 11 ss. 
festaciones de autonomía; pero de tales manifestaciones o, mejor dicho, del pacto tácito que las mismas implican, no deriva, de acuerdo con el mismo diálogo, la fuerza obligatoria de las leyes; sólo nace un deber del súbdito: el de someterse a los nómoi, y tal deber es consecuencia del mencionado pacto tácito. Según la Anerkennungstheorie --en cualquiera de sus variantes- la obligatoriedad del derecho dimana, en cambio, de su reconocimiento, ya sea por cada uno de los particulares, ya, como en las llamadas teorias generales sobre el mismo punto, por la generalidad de los integrantes de un pueblo. 50

Eduardo García Máynez

INSTTTUto de INVESTigaciones Filosóficas

Universidad Nacional Autb́noma de México

50 Sobre las teorias del reconocimiento y su clasificación: Hans Ludwig Schreiber, Der Begriff der Rechtspflicht (El concepto del deber juridico), Walter de Gruyter, Berlín, 1966, especialmente Pp. 105-117. 